\title{
Why is it Difficult to Train a Wolf Employee? - A HR Insight to Tame the Untamed
}

\author{
Gokulshankar Sabesan ${ }^{1}$, Remya Vallathol ${ }^{1}$, Kavitha Gokulshankar ${ }^{2}$, \\ Mohanty $\mathrm{BK}^{3}$, Ranjith $\mathrm{MS}^{4 *}$
}

\section{ABSTRACT}

The wolf is an aggressive beast genetically related to the dogs. Unlike dogs, the wolves are difficult to be trained and tamed. There are employees in the corporate who exhibit the behavior of wolf. This paper presents the fact on how the wolf like behavior of employees affects the corporate and gives the management strategies to the Human Resource department to manage such employees.

\section{Keywords: Wolf, Human Resources, Corporate, Employee}

There was a picture of an aggressive wolf which was in the social media with a caption that the tiger and the lion may be more powerful... but the Wolf does not perform in the circus. It was sheer truth which initiated an interesting discussion on why wolves are not in the circus. The understanding of the wolves and their behaviour would help in the understanding of certain employees in the corporate or in other offices who exhibit a wolf- like character. Swami and Ranganathan (1) have reported on the use of jungle wisdom and knowledge on animal behaviors for corporate management and governance. Firstly, let us get away with the myth that wolves are associated with something evil and then try to understand the behavior of these animals which will help us to answer the first question raised in the article. Wolf is best known and well researched among the wildlife species and there are more books written about it. (2)

\section{Establishing territory}

The wolves in corporate usually operate as a pack. A typical wolf pack is also comprised of several members. Like how an adult male and female lead the pack, in corporate too a senior person (not by age, but by putting in several years of experience in the same organization) would lead the team of the likeminded people employees who would refuse implementation of new changes in the existing process and would indirectly scheme against any new leader who takes

\footnotetext{
${ }^{1}$ Faculty of Medicine, AIMST University, Sungai Petani, Malaysia

${ }^{2}$ Freelance writer

${ }^{3}$ Faculty of Medicine, UniKL-RCMP, Ipoh, Malaysia

${ }^{4}$ Faculty of Medicine, Quest International University Perak, Ipoh, Malaysia

*Corresponding Author

(C) 2015 I G Sabesam, R Vallathol, K Gokulshankar, B Mohanty, M Ranjith; licensee IJIP. This is an Open Access Research distributed under the terms of the Creative Commons Attribution License (http://creativecommons.org/licenses/by/2.0), which permits unrestricted use, distribution, and reproduction in any Medium, provided the original work is properly cited.
} 
over the corporate. They feel that their territory is at stake and would therefore like to mark their presence in all the events that take place in the organization and do things which will disdain other employees to work in their domain.

\section{Eavesdropping}

Wolves have excellent hearing and can turn their large ears halfway around their heads to locate the direction from where the sound is coming from in the deep jungle. Such a ability also exists in the corporate wolves which have the habit of eaves dropping all the important phone calls, any remarks told by the group leaders against the team members or colleagues even while doing their regular routine chores. Their hungry ears can pick every conversation (also gossips) of the employees which will be used by the corporate wolves for character assassination of any of the

people who have a disagreement with them or even used just to gain importance from the top management.

\section{Team effort in feast}

A pack of wolves are united and focused and may chase a moose for hundreds of yards until it slows down with exhaustion. Then the wolves move in for the kill. The team work is such that each wolf bites a different part of the prey, from its nose, neck, flanks, rump, legs and even the neck is not spared. This team work usually helps the wolves to hunt and kill prey that is much larger than them. A $590 \mathrm{~kg}$ moose is no match for a pack of six to eight wolves. Each of the wolves may be around $45 \mathrm{~kg}$ only. This striking ability is seen in corporate wolves. The wolf employees as a pack can scheme, wait for an appropriate opportunity and attack a leader or manager. The manager in most cases will be unaware of the threat and which can lead to the annihilation of the career path of the manager in that organization.

\section{Unwillingness to be trained}

It is possible to train even the powerful wild beasts like lion or tiger in a circus by the trainers. But it is practically impossible to train a wolf. This could be the main reason on why we do not see a wolf performing in a circus. The difficulty to train wolves basically is due to their intrinsic character of suspiciousness and unwillingness to have belief in the trainer. Similarly in corporate too, the wolf employees do not believe in their manager or team head. They prefer to work in their own style and refuse to get trained in the soft skills/ other skills that are required to be updated from time to time. This unwillingness to learn or change usually results in confrontation with their bosses or managers.

\section{Is wolf really misunderstood?}

The wolf is a symbol of free-will with the ability to escape. It may be another reason why it is difficult to train a wolf employee. It is quite strange on why the dogs which is the closest relative in the evolutionary biology (2) is known for its loyalty and friendliness while wolf is depicted as a symbol of evil often related to demonic and brutal behavior. Several hundreds of years of 
domestication would have made the dogs friendlier which originally would have been savage in the wild jungles. Though, genetically dogs and wolves have so much of a similarity, biologists believe that physiologically they are different. The hormonal levels of the wolf are quite different which makes it intrinsically wild (3). The perception of wolf as a beast is usually also a reflection of the stories which we have heard or read from childhood. For instance the story of little red riding hood would never give a good image of wolf to a child. Wolf's 'untamed wildness' and its power of senses should not be underestimated. Wolf is one of the animals which had successfully adapted it to the evolutionary changes and survived the period of time. Similarly even with the changing environment in a corporate the wolf employees remain adapted and survive for a longer time under different leaderships. The wolf is best known of its team work, loyalty to its pack and excellent vision and a fine smell of finding and tracking. The wolf employees also have these characters which when channelled properly can be exploited to achieve higher targets in a corporate. Wolf employees usually need a strong leadership of a lion boss whom they never dare to challenge. If the boss of a wolf employee is timid and soft in heart, then it would be disaster to manage the untamed wilderness of a wolf. In the South American folk-fore wolf is a 'path finder'. It depends on the corporate management or human resource department to effectively manage the wolf employee to get the best out of him/her, else the wolf finds its own path; the path of its survival even at the expense of others.

\section{REFERENCES}

1. Swami Sukhabodhananda and Ranganathan S. 2012. Jungle wisdom for corporate management; Lessons from university of nature. Sudhindra, Bangalore, India

2. Weide, B. \& Tucker, P. 1995. There's a Wolf in the Classroom! Minneapolis: Carol/Rhoda Press.

3. Udell, Monique A.R, and C.D.L Wynne. “A Review of Domestic Dogs' (Canis Familiaris) Human-Like Behaviors: Or Why Behavior Analysts Should Stop Worrying and Love Their Dogs.” Journal of the Experimental Analysis of Behavior 89.2 (2008): 247-261. PMC. Web. 14 Sept. 2015.

4. Mech, L. David; Boitani, Luigi (2003). Wolves: Behaviour, Ecology and Conservation. University of Chicago Press. ISBN 0-226-51696-2. 